\title{
Evaluation of a semi-empirical model for predicting fine root biomass in compositionally complex woodland vegetation
}

\author{
Ayalsew ZERIHUN ${ }^{\mathrm{a}, \mathrm{b}, \mathrm{e}}$, Christian AMMER ${ }^{\mathrm{c} *}$, Kelvin D. MONTAGU ${ }^{\mathrm{d}}$ \\ ${ }^{a}$ Forest Resources Research, NSW Department of Primary Industries, PO Box 100, Beecroft, NSW 2119, Australia \\ ${ }^{\mathrm{b}}$ Cooperative Research Centre for Greenhouse Accounting, GPO Box 475, ACT 2601, Australia \\ ${ }^{\mathrm{c}}$ Bavarian Forest Institute, Unit for Silvicultural Research, Am Hochanger 11, 85354 Freising, Germany \\ ${ }^{\mathrm{d}}$ School of Natural Sciences, University of Western Sydney, Penrith, NSW 1797, Australia \\ e Present address: Curtin University of Technology, Margaret River Education Campus, PMB 1, Margaret River, WA 62851, Australia
}

(Received 8 July 2006; accepted 3 October 2006)

\begin{abstract}
We used measures of plant size, distribution and root core data to evaluate capability of the model of Ammer and Wagner [2] for spatially explicit prediction of fine root biomass (FRB) in Eucalyptus populnea-dominated woodlands from xeric and mesic regions of Australia. Tree diameter and height were tested as proxy variables for plant size. For the xeric site, which had no understorey grass cover, both the height- and diameter-based models gave reasonable estimates of FRB. However, the height-model provided a better match to the measured data than the diameter-model. For the mesic site, which had a substantial ground cover dominated by $\mathrm{C}_{4}$-grasses whose contribution to FRB could not be captured by the model, neither the height- nor the diameter- model was able to predict FRB satisfactorily. This was also the case even when the contribution of the $\mathrm{C}_{4}$-grasses to FRB was estimated and accounted for after $\delta^{13} \mathrm{C}$ analysis of fine root samples. Overall, while it is evident that the model can be a useful tool for estimating FRB from aboveground stand inventory in both even-aged plantations and compositionally complex natural vegetation, it is also clear that it does not always provide satisfactory prediction, e.g., the mesic site. Thus, to improve the wider applicability of the model further work is needed to identify why it fails and situations it is likely to be useful.
\end{abstract}

Eucalyptus populnea / biomass prediction / root radial distribution / rangeland / woodland

Résumé - Évaluation d'un modèle semi-empirique pour la prédiction de la biomasse des racines fines dans la végétation composite et complexe d'une zone boisée. Nous avons utilisé des mesures de dimensions des plants, de distribution et de carotte de racine pour évaluer la capacité du modèle de Ammer et Wagner [2] pour une prédiction spatiale explicite de la biomasse des fines racines (FRB) dans des zones boisées où Eucalyptus populnea est dominant, dans les régions très sèches et mésoïques d'Australie. La hauteur et le diamètre des arbres ont été testés comme des variables de procuration de la dimension du plant. Pour le site sec qui n'avait pas de sous-bois herbeux, l'un et l'autre des modèles basés sur la hauteur et le diamètre donnent une estimation raisonnable de FRB. Cependant, le modèle hauteur fourni une meilleure adéquation aux données mesurées que le modèle diamètre. Pour le site mésoïque, qui a une couverture herbeuse importante dominée par des espèces en $\mathrm{C}_{4}$ et dont la contribution à FRB ne peut pas être prise en compte par le modèle, ni l'un ni l'autre du modèle hauteur et du modèle diamètre était capable de prédire FRB correctement. C'était aussi le cas même quand la contribution des herbes en $\mathrm{C}_{4}$ à FRB a été estimée et justifiée par des analyses de $\delta^{13} \mathrm{C}$ de fines racines. En général, quoiqu'il soit évident que le modèle peut être un outil utile pour estimer FRB à partir d'un inventaire au-dessus du sol dans les deux plantations équiennes et dans la végétation naturelle composite, il est aussi clair que cela ne permet pas toujours une prédiction satisfaisante, par exemple pour le site moyennement sec. Alors, pour améliorer une plus large applicabilité du modèle davantage de travail est nécessaire pour identifier pourquoi il ne convient pas et les situations où il est possible de l'utiliser.

Eucalyptus populnea / prédiction de la biomasse / distribution radiale des racines / prairie / zone boisée

\section{INTRODUCTION}

In forest and woodland ecosystems, the biomass of fine roots (diameter $<2 \mathrm{~mm}$ ) generally constitutes a small component of the total (above- and below-ground) biomass pool $[14,24]$. However, as the main structures for acquisition and uptake of belowground resources such as water and nutrients $[8,20]$ and due to their rapid turnover, fine roots play a crucial part in the functioning and productivity of forest ecosystems. Clearly, thus, ability to quantify the pool size of fine

* Corresponding author: cha@lwf.uni-muenchen.de roots is a key component of understanding the productivity and functioning of forest and woodland ecosystems.

Traditionally, estimates of pool sizes of fine roots have been obtained through labour intensive and difficult procedures such as coring, trenching or variants thereof [3]. However, the difficult nature of these methods means that studies on roots have markedly lagged those of aboveground systems [23]. One option for overcoming the relative scarcity of information on fine root systems would be to develop models that can predict fine root biomass (FRB) using information that requires relatively less effort to gather [4]. However, few such models have been developed. The models developed to-date can be 
categorised into three groups: (1) those that attempt to model FRB as a proportion of total root biomass [10, 12]; (2) allometric models that relate FRB to individual tree diameter [5]; and (3) models that provide spatial FRB estimates using stand inventory, distribution of plants and extent of root spread information $[1,2,11,15]$.

The success of the first group of models in predicting FRB is generally low (e.g., proportion of variance in FRB explained by such models has been less than $36 \%$ ) $[10,12]$. The second and third groups of models appear to give improvements over the first type in part because some of the key factors that influence root distribution and density are explicitly incorporated in these models. Accordingly, the models presented by Ammer and Wagner [2] and Lee et al. [11] were shown to provide satisfactory prediction of FRB pools for pure or near pure forest stands. However, estimations of FRB at various spatial scales are also needed for compositionally much more complex vegetation. Such information would improve terrestrial ecosystem models and their estimates of carbon cycling [11]. Thus, the objective of this work was to evaluate the suitability of the model of Ammer and Wagner [2] for predicting FRB pools in compositionally diverse woodland vegetation from contrasting climatic regions in northeast Australia.

\section{MATERIALS AND METHODS}

\subsection{Data source}

The data used in this work were collected as part of a larger project that examined patterns of below- and above-ground biomass in $\mathrm{Eu}$ calyptus populnea woodland ecosystems along a rainfall gradient in northeast Australia [25]. Here, data from the xeric- and mesic-end of the rainfall gradient are used for this retrospective fine root biomass modelling analysis. Site descriptions, vegetation inventory and root sampling are fully detailed in Zerihun et al. [25]. Briefly, the mean annual rainfall and temperature at the xeric and mesic sites are $367 \mathrm{~mm}$ and $19.5{ }^{\circ} \mathrm{C}$, and $1103 \mathrm{~mm}$ and $22.1{ }^{\circ} \mathrm{C}$, respectively. The vegetation at both sites is open woodland whose biomass is dominated (mesic site) or co-dominated (xeric site) by Eucalyptus populnea. At the xeric site the vegetation was composed of many woody plant species (density ca. $2600 \cdot \mathrm{ha}^{-1}$ of which one-third had height $\geq 2 \mathrm{~m}$ ), the ground layer had little or no grass cover. The woody plant density at the mesic site averaged $610 \cdot \mathrm{ha}^{-1}$ (about a quarter of which were $2 \mathrm{~m}$ or taller); the ground layer vegetation contained significant grass cover dominated by native $\mathrm{C}_{4}$ grasses and a few forbs (M.B. Hoffmann and S.G. Bray, pers. com.).

For vegetation inventory and root sampling, five transect strips $(100 \mathrm{~m} \times 4 \mathrm{~m})$ were established at each site. Because roots of woody species in dry environments are known to reach deep soil horizons [16] in each transect eight soil core samples (from randomly selected locations) were taken to a depth of $100 \mathrm{~cm}$, using a $100 \mathrm{~mm}$ internal diameter steel corer, thus yielding a total of 40 root core samples per site. Core samples at the xeric site were taken at: $0-15,15-30,30-50,50-75$ and $75-100 \mathrm{~cm}$ depth increments. At the mesic site, the last two depth increments were taken as one unit, i.e., $50-100 \mathrm{~cm}$. Roots were washed over a series of sieves and sorted into several size classes. The data used here however refer to the fine root (diameter $<2 \mathrm{~mm}$ ) component only. For each root core sample, inventory of tree and shrub vegetation was carried out within a $15 \mathrm{~m}$ radius. The inventory data included identity of woody species, their height, diameter at $30 \mathrm{~cm}$ height $\left(D_{30}\right)$, distance and bearing from root core point.

\section{2. $\delta^{13} \mathrm{C}$ analysis}

The ground layer vegetation at the mesic site was dominated by $\mathrm{C}_{4}$ grasses. In contrast, the upper strata of vegetation contained exclusively $\mathrm{C}_{3}$ woody species. Since $\mathrm{C}_{3}$ and $\mathrm{C}_{4}$ species have distinct $\delta^{13} \mathrm{C}$ values, this distinction was utilised for estimating contribution of the ground layer vegetation to total FRB based on the $\delta^{13} \mathrm{C}$ of fine roots samples. For each core, fine root samples were divided (and analysed for $\delta^{13} \mathrm{C}$ ) into two depth increments: $0-15 \mathrm{~cm}$ and $15-100 \mathrm{~cm}$ (i.e., fine roots from the $15-30,30-50$ and $50-100 \mathrm{~cm}$ depth increments were combined). $\delta^{13} \mathrm{C}$ analysis was carried as described in Krull and Bray [9]. In brief, fine root samples from these depth increments were pulverised, and sub-samples of 1-2 mg (containing between 50 and $95 \mu \mathrm{mol} \mathrm{C}$ ) were weighed into clean tin capsules and sealed. The sealed samples were combusted and analysed for ${ }^{13} \mathrm{C}$ using a Europa Scientific Geo 20/20 Automated Nitrogen Carbon Analysis - Mass Spectrometer. Stable carbon isotopic results are presented in $\delta$ notation as per mill $(\%)$ relative to carbon-isotopic ratio of Pee Dee Belemnite standard. The standard deviation of replicate fine root samples from the surface soil $(0-15 \mathrm{~cm})$ was $<0.2 \%$ $(n=4)$. The data from this analysis were used to estimate the amount of FRB contributed by woody $\left(\mathrm{C}_{3}\right)$ vegetation as described in Ludlow et al. [13]:

$$
\begin{gathered}
w F R B_{0-15 \mathrm{~cm}, i}=\left[\frac{\left(\delta_{s, 0-15 \mathrm{~cm}, i}-\delta_{4}\right)}{\left(\delta_{3}-\delta_{4}\right)}\right] \times t F R B_{0-15 \mathrm{~cm}, i} \\
w F R B_{15-100 \mathrm{~cm}, i}=\left[\frac{\left(\delta_{s, 15-100 \mathrm{~cm}, i}-\delta_{4}\right)}{\left(\delta_{3}-\delta_{4}\right)}\right] \times t F R B_{15-100 \mathrm{~cm}, i}
\end{gathered}
$$

In equation (1), $w F R B_{0-15} \mathrm{~cm}, i$ refers to FRB estimate for the woody $\left(C_{3}\right)$ vegetation, $\delta_{s, 0-15 \mathrm{~cm}, i}$, is the $\delta^{13} \mathrm{C}$ of the bulk fine root sample from the $0-15 \mathrm{~cm}$ depth increment for core ${ }_{i} ; \delta_{4}$ is the $\delta^{13} \mathrm{C}$ value for a pure $\mathrm{C}_{4}$ grass fine root sample $(-13.11 \%) ; \delta_{3}$ is the $\delta^{13} \mathrm{C}$ of pure E. populnea $\left(\mathrm{C}_{3}\right)$ fine root sample $(-27.00 \%)$; and $t F R B_{0-15 \mathrm{~cm}, i}$ is the measured total FRB for the $0-15 \mathrm{~cm}$ depth increment of core $_{i}$. Estimation of woody FRB for the 5-100 cm increment was carried out as shown in equation (2). Total woody FRB estimates for a given core $(0-100 \mathrm{~cm})$ were obtained by adding the results from equations (1) and (2).

\subsection{Modelling}

The modelling approach employed here is fully described in Ammer and Wagner [2]. In brief, for any point in a stand, the model computes the so-called relative fine root biomass $(r F R B)$ contributed by trees that surround the point of interest based on the size and distance of plants to that point, and heuristic assumption regarding the maximal root spread (see below). In the original model root spread and/or distribution are described as a function of diameter at breast height $(d b h)$. The total relative fine root biomass $(\operatorname{Tr} F R B)$ at a given point is calculated as the additive contribution of the $r F R B$ for the trees in the vicinity of the sampled point. 
The respective algorithms of the original model are formulated as follows:

$$
R D_{3}=\frac{d b h}{6}
$$

assuming a maximum root spread distance of $10 \mathrm{~m}$ for a tree of $60 \mathrm{~cm}$ diameter at breast height, where $R D_{3}$ is the maximum root spread distances in $\mathrm{m}$ and $d b h$ is the diameter at breast height in $\mathrm{cm}$,

$$
R D_{2}=\frac{2}{3} R D_{3}, \quad R D_{1}=\frac{1}{3} R D_{3} \text { and, } R D_{0}=0,
$$

where $R D_{2}$ and $R D_{1}$ are two thirds and one third respectively of $R D_{3}$ and $R D_{0}$ marks the trunk,

$$
r F R B_{0}=\frac{d b h}{100}
$$

where $r F R B_{0}$ is the relative fine root biomass at distance $R D_{0}$ (trunk),

$$
r F R B_{1}=\frac{5}{3} r F R B_{0}, \quad r F R B_{2}=\frac{5}{6} r F R B_{0} \text { and } r F R B_{3}=0,
$$

where $r F R B_{1}, r F R B_{2}$ and $r F R B_{3}$ are the relative fine root biomasses at the distances $R D_{1}, R D_{2}$ and $R D_{3}$.

Based on the distances $R D_{0}$ to $R D_{3}$ a polynomial of third degree for the dbh of each tree was calculated using the Gregory-Newtonprocedure to fit a polynomial of $n$th degree to $n+1$ equidistant points of support. This allows the calculation of the $r F R B$ of each tree of a stand at any point $x, y$. The respective formulas are:

(1) if $D \geq R D_{3}$, then $r F R B=0$, where $D$ is the distance between the tree's trunk and $x, y$

(2) if $D<R D_{3}$, then $r F R B$ of a tree at point $x, y$ is calculated as follows:

$$
\begin{aligned}
h= & R D_{2}-R D_{1} \\
b_{0}= & r F R B_{0} \\
b_{1}= & \frac{\left(r F R B_{1}-r F R B_{0}\right)}{1 ! h} \\
b_{2}= & \frac{\left(\left(r F R B_{2}-r F R B_{1}\right)-\left(r F R B_{1}-r F R B_{0}\right)\right)}{2 ! h^{2}} \\
b_{3}= & \frac{\left(\left(r F R B_{3}-r F R B_{2}\right)-\left(r F R B_{2}-r F R B_{1}\right)\right)}{3 ! h^{3}} \\
& -\frac{\left(\left(r F R B_{2}-r F R B_{1}\right)-\left(r F R B_{1}-r F R B_{0}\right)\right)}{3 ! h^{3}} \\
r F R B_{x, y}= & b_{0}+b_{1}\left(D-R D_{0}\right)+b_{2}\left(D-R D_{0}\right)\left(D-R D_{1}\right) \\
& +b_{3}\left(D-R D_{0}\right)\left(D-R D_{1}\right)\left(D-R D_{2}\right) .
\end{aligned}
$$

Total $r F R B(\operatorname{TrFRB})$ at point $x, y$ was calculated as:

$\operatorname{Tr} F R B=\sum_{i=1}^{n} r F R B_{i}$, where $i$ is the number of the recorded trees.

Thus it is assumed that the total amount of fine roots at a given point results from additive contributions of the trees.

However, as many of woody plants at the two sites investigated here had not reached breast height $(1.3 \mathrm{~m})$ until the survey or will never do so, the model was adjusted. Two approaches were tested. Both approaches are based on the observation that lateral root spreads generally increase with an increase in plant size [19]. In the first approach, the assumed maximum root spread in $\mathrm{m}$, which was originally defined as $d b h / 6$, was set as being equal to tree height $(H)$. In the second approach, maximum root spread was calculated as diameter (at

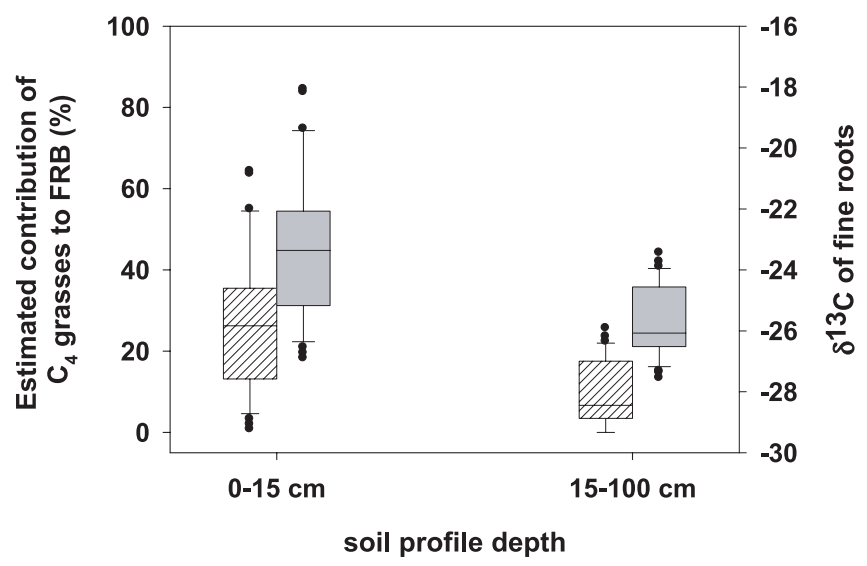

Figure 1. Distribution of $\delta^{13} \mathrm{C}$ of fine roots from the $0-15 \mathrm{~cm}$ and 15-100 cm depth increments (grey box) and the corresponding estimates of the contribution of the ground layer vegetation $\left(\mathrm{C}_{4}\right.$ grasses $)$ to the total fine root biomass (hashed box) at the mesic site. The boxes depict the inter-quartile ranges of the data, while the horizontal lines within boxes denote the respective medians.

$30 \mathrm{~cm}$ tree height $) \times 50$. In addition, the $r F R B$ at the trunk (distance $=$ $0 \mathrm{~m}$ ) was defined as $h / 100$ and $\log _{e}\left(D_{30}\right)$, respectively. These values fit data best, i.e. the regressions between $\operatorname{TrFRB}$ based on these settings and measured FRB showed the highest $R^{2}$ compared to other approaches. All other settings of the model described above remained unchanged. For each site, the model was parameterised using the fine root biomass data. In order to estimate the bias of the measured and predicted statistics, bootstrap resampling was conducted (random resampling with replacement from the original sample, 1000 samples, $n=40$ ) according to Quinn and Keough [17].

\section{RESULTS}

The $\delta^{13} \mathrm{C}$ of fine roots from the surface $(0-15 \mathrm{~cm})$ and deeper $(15-100 \mathrm{~cm})$ soil is shown in Figure 1 . The $\delta^{13} \mathrm{C}$ of fine roots from the surface soil were considerably more variable than those at $15-100 \mathrm{~cm}$, indicating the high spatial variability in the contribution of woody plants and grasses to FRB in the surface soil, and the dominance of woody fine roots at $15-100 \mathrm{~cm}$ depth, respectively. On average, however, fine roots from $0-15 \mathrm{~cm}$ depth had $\delta^{13} \mathrm{C}$ that was significantly $(p<0.05)$ more enriched $(-23.3 \%)$ than fine roots from the $15-100 \mathrm{~cm}$ depth increment $(-25.7 \%)$. Accordingly, the native $\mathrm{C}_{4}$ grasses on average contributed $27.1 \%$ to the measured total fine root biomass from the surface soil, whereas at the $15-100 \mathrm{~cm}$ depth fine root of $\mathrm{C}_{4}$ grasses accounted for only $9.5 \%$ of the total FRB (Fig. 1).

Model estimates of $r F R B$ were derived using either diameter at $30 \mathrm{~cm}\left(D_{30}\right)$ or plant height to define root spread and distribution of $r F R B$. The results showed that for the xeric woodland site, using tree height to define the spread and distribution of roots explained a much larger percentage of the variation in the measured FRB than using $D_{30}, 60 \%$ vs. $34 \%$, respectively (Tab. I).

The mean fine root biomass was moderately higher at the xeric than the mesic site, but the standard errors of the means 
Table I. Relationship between measured fine root biomass per core $(m F R B)$ and the relative fine root biomass $(r F R B)$ predicted by the model of the form: $m F R B=\beta_{o}+\beta_{1} r F R B$. MSE $=$ mean square error.

\begin{tabular}{lcccccc}
\hline Xeric site & $\beta_{o}$ & $\beta_{1}$ & $R^{2}$ & MSE & $P>F$ & $n$ \\
\hline${ }^{\S} D_{30}$ & 177.8 & 6.12 & 0.34 & 8154 & 0.0001 & $38(40)$ \\
${ }^{\S} H$ & 183.0 & 431.9 & 0.60 & 6999 & 0.0001 & $38(40)$ \\
\hline Mesic site & & & & & & \\
${ }^{\S} D_{30}$ & 186.0 & 2.82 & 0.09 & 12265 & 0.040 & $38(40)$ \\
${ }^{\S} H$ & 181.0 & 59.8 & 0.10 & 12063 & 0.028 & $38(40)$ \\
\hline
\end{tabular}

$\S$ Denote measures of plant dimension that were used for defining root spread and distribution foe estimating $r F R B$.

and the medians of the two sites were quite comparable (cf. Tabs. II and III). This was particularly true for the bootstrap estimates. Moreover, the bias between the measured mean and the related bootstrap estimator was negligible (Tabs. II and III).

The predicted stand average FRB derived from tree height was closer to the measured mean FRB than the mean obtained from $D_{30}$. This was further supported by the bootstrap analyses. For example, the standard error and the confidence intervals of the bootstrap mean and median calculated on the basis of tree height were more comparable to the bootstrap statistics of the measured mean than the corresponding measures calculated by using $D_{30}$ (Tab. II). Accordingly, the frequency distribution of bootstrap means of the measured and predicted data were rather similar for the FRB values calculated on the basis of tree height (Fig. 2).

For the mesic woodland site the relationships between measured FRB and $r F R B$, though significant $(p<0.05)$, were very weak (Tab. I). This was the case whether tree height or $D_{30}$ were used to define root spread. Consequently, the models overestimated stand mean FRB considerably and failed to reflect the variance inherent the measured root data (Tab. III, Fig. 3). This resulted in substantially differing distributions of predicted bootstrap means and medians from the bootstrap estimates of the measured data (Fig. 3).

\section{DISCUSSION}

The aim of this work was to evaluate the capability of an inventory based semi-empirical model for predicting fine root biomass in compositionally complex woodland vegetation from xeric and mesic environments in eastern Australia. The results showed that the model predicted mean fine root biomass of the E. populnea and shrub dominated plant community at the xeric site reasonably well. Similar results were obtained when the model was applied to monospecific evenaged Norway spruce stands in Germany [2]. In contrast, the model failed to adequately predict mean FRB of the E. populnea community at the mesic site.

In attempting to explain the differential success of the model in predicting FRB at the two sites it should be noted that the model uses measures of tree dimensions (height or diameter) as input. While this applies irrespective of site, it becomes a critical factor if the vegetation at the different sites has components that contribute to fine root biomass whose contributions are not fully captured (via height or diameter) as model inputs. In this regard, it is important to highlight that at the xeric woodland site the understorey vegetation was dominated by shrub species with little or no grass cover. The lack of grass groundcover made it possible to generate a complete inventory (e.g., plant height, distance and for large plants $D_{30}$ ) for practically all plants within $15 \mathrm{~m}$ of each soil-core sampling point. This information enabled the potential contribution of nearly all plants to FRB of a given core to be accounted for based on the size and distance of each plant from the soil core sampling point. At the mesic site, on the other hand, the vegetation had a significant grass cover. Thus, although the relevant metrics were recorded for the woody plant component of the vegetation, no meaningful model inputs could be recorded for the grass component of the plant community. Consequently, we excluded FRB of the grass component of the vegetation according to the results of the $\delta^{13} \mathrm{C}$ analysis, and the model was re-run using FRB data for the woody vegetation. However, in contrast to our expectation, this measure did not improve the prediction of the model at the mesic site (Tab. III, Fig. 3). This indicates that inability of the model to predict FRB is not because of failure to account for the direct contribution of the grass vegetation. Therefore, effect of the grass vegetation, if any, is likely to be indirect. For example, grass competition might have modified biomass allocation patterns of woody vegetation at the expense of roots as has been observed in some species [6]. The occurrence and extent of such an effect was not examined in our work and hence could not be accounted for in the modelling analysis. Summarising, the modelling results for the mesic site show that the model is not applicable for all situations in its current form.

However, the importance of accounting for all potentially contributing vegetation is evidenced by the results from the xeric site. At this site, although both the $D_{30^{-}}$and heightbased models produced statistically equivalent stand average FRB predictions, the range and distribution of height-derived predictions matched the measured data better than predictions derived from $D_{30}$ inputs (Tab. II, Fig. 2). This may be because almost all species had a measure of height but not $D_{30}$ particularly for small shrubs and shrub clusters - thus when using height the contributions of nearly all plants are included but not when $D_{30}$ is used; clearly indicating that it is important to account for all plants that are likely to contribute to fine root biomass.

One possibility that leads to disagreement between measured and predicted values is heterogeneity of soil resource distribution (or resource patchiness). It is well known that root distribution and proliferation respond to resource patchiness $[7,18]$, but such possibilities are not incorporated in the model. However, the issue of resource heterogeneity is generic. Resource patchiness can therefore serve as an explanation for the differences in model performance between the xeric and mesic sites only if resource heterogeneity is greater 
Table II. Measured and predicted fine root biomass at the xeric site $(n=40)$, bootstrap sample $=1000$.

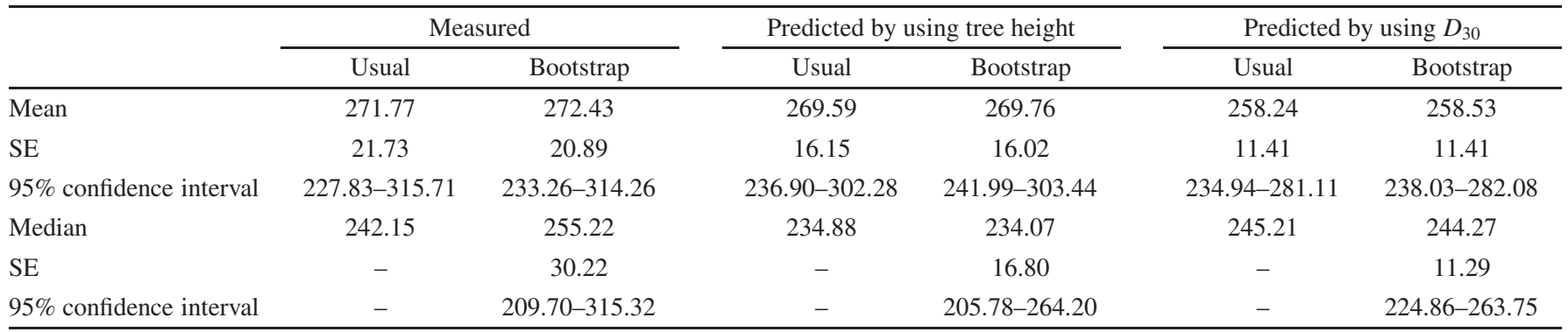

Table III. Measured and predicted fine root biomass at the mesic site $(n=40)$, bootstrap sample $=1000$.

\begin{tabular}{|c|c|c|c|c|c|c|}
\hline & \multicolumn{2}{|c|}{ Measured } & \multicolumn{2}{|c|}{ Predicted by using tree height } & \multicolumn{2}{|c|}{ Predicted by using $D_{30}$} \\
\hline & Usual & Bootstrap & Usual & Bootstrap & Usual & Bootstrap \\
\hline Mean & 247.27 & 246.76 & 293.41 & 293.54 & 293.01 & 293.01 \\
\hline SE & 18.97 & 18.92 & 6.54 & 6.32 & 6.13 & 5.91 \\
\hline $95 \%$ confidence interval & $208.91-285.64$ & $210.83-283.19$ & $280.18-306.64$ & $281.15-306.18$ & $280.61-305.41$ & $281.09-304.48$ \\
\hline Median & 257.30 & 252.55 & 298.93 & 298.24 & 301.33 & 301.35 \\
\hline SE & - & 20.14 & - & 5.90 & - & 6.06 \\
\hline $95 \%$ confidence interval & - & 211.70-287.35 & - & $284.48-310.34$ & - & $286.57-312.42$ \\
\hline
\end{tabular}

at the mesic than xeric site. However, the relevant data are not available to evaluate this possibility.

An implicit assumption of the model is that the extent of lateral root distribution is constant along a rainfall gradient. Whether this is so is not tested. Thus, an additional possibility (for the poor agreement between the measured and predicted FRB at the mesic-site) could be that the distance dependence of root distribution changes along a rainfall and/or moisture availability gradient. However, from analysis of global datasets, Schenk and Jackson [19] found no evidence that lateral root spread for trees varies with mean annual rainfall in the range 50 to $1000 \mathrm{~mm}$, which envelopes the rainfall ranges of our two study sites. In fact model variations assuming an extended root spread for the mesic site did not lead to better results for the relationship between predicted and measured data (data not shown). However, Schenk and Jackson [19] showed that the lateral root spread is strongly correlated to aboveground biomass. The inventory at the mesic site where tree height and diameter were much higher than at the xeric site therefore probably did not include all trees contributing roots to a given soil core. In this work the maximum radial extent of tree roots in metres was set equal to tree height and $D_{30} \times 50$ respectively. However, for logistical reasons we could only register the trees within $15 \mathrm{~m}$ around the core-sampling points. The maximum radial extent of trees is likely to vary depending on environmental conditions and size of trees but generally ranges from 1.5 to 4 times tree height [22]. In absolute distance terms, eucalypts from semi-arid environments show considerable radial root growth (e.g., ca. $20 \mathrm{~m}$ for E. camaldulensis [26], up to $39 \mathrm{~m}$ in $E$. globulus [22], in excess of 15-16 m for E. leucoxylon and $E$. trivalva (cited in Stone and Kalisz [21]). The fact that our modelling and inventory of vegetation around each core were limited to $15 \mathrm{~m}$, could underestimate the potential contribution of plants that are located beyond these distances. However, since root density declines exponentially with distance from a tree [22], exclusion of the potential contributions of distant plants is unlikely to cause significant underestimation of FRB. Furthermore, the modelled FRB did not show systematic underestimation which would be expected if the maximal radial root spread used in the model $(15 \mathrm{~m})$ was less than the actual spread.

\section{Potential limitations, implications and applications}

As indicated in the Introduction, the model used here was developed for monospecific even-aged spruce stands. For monospecific stands (e.g., plantations), it is plausible to assume that the pattern of lateral root distribution is similar for all plants that make up the stand. This assumption is implicitly carried though in our application of the model to woodland vegetations with multi-species composition. If this assumption is invalid (i.e., the many plant species that make up the plant community have vastly different lateral root distribution patterns), then a reasonable agreement between predicted and measured root biomass may not be obtained. Justifiably, thus, the good agreement between the predicted and measured FRB at the low rainfall site implies that root distribution patterns in this xeric landscape are broadly similar and defined primarily by moisture availability irrespective of differences in plant (functional and/or growth) form. This means on the other hand, that species specific differences in lateral root spread and fine root distribution might be more pronounced at the high rainfall site. Consequently, differences between reality and a 

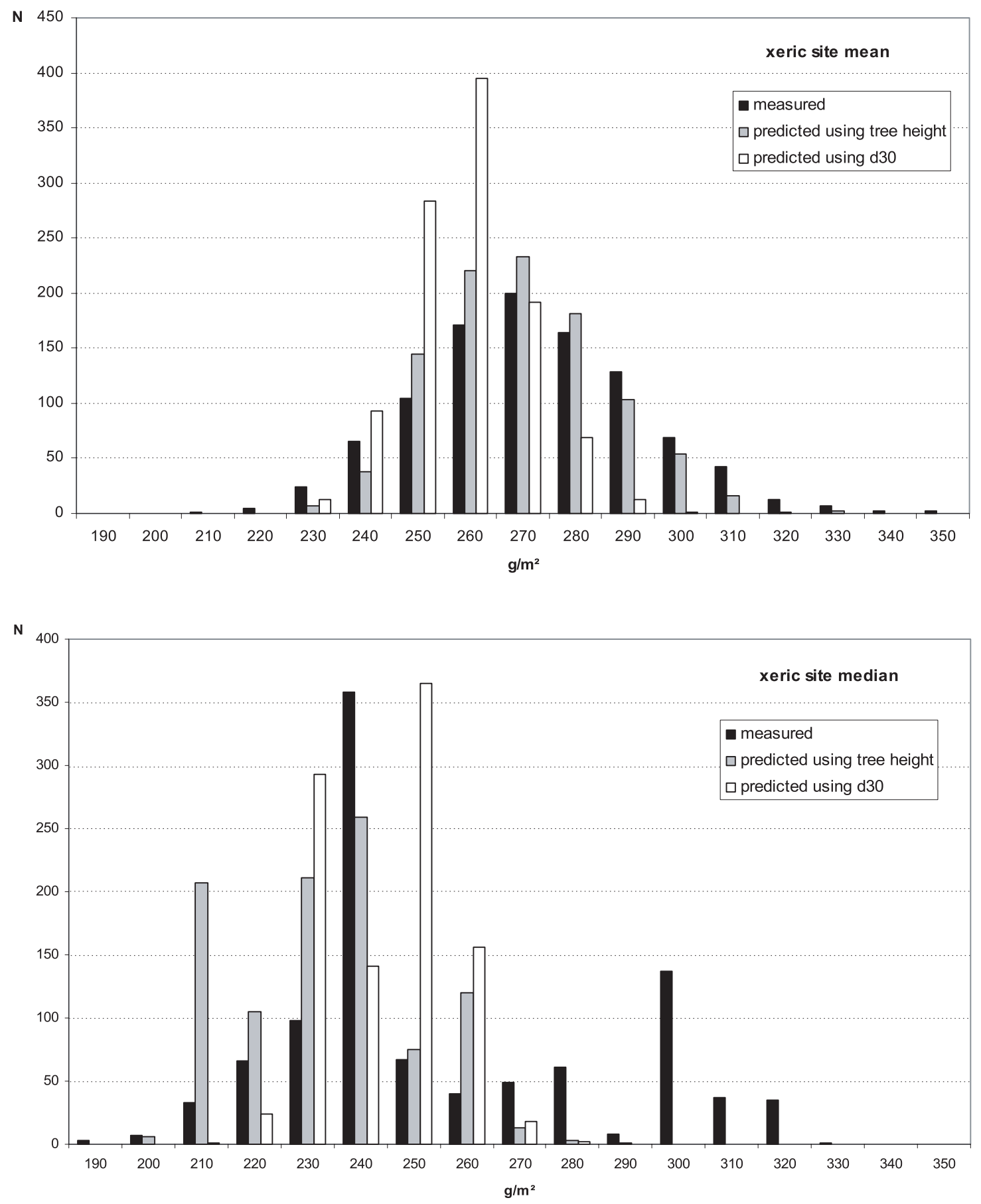

Figure 2. Frequency distributions of the bootstrap means and medians for the xeric site.

model which does not distinguish between the rooting systems of woody plant species are likely (Tab. III).

The model results indicate that even in compositionally complex vegetation, FRB could be predicted reasonably well provided complete inventory data are available for all plants around sampling points. Like most models, parameterisation of the model will be required before it can be used to provide prediction of FRB for a new environment and vegetation type.
Arguably, further evaluation under diverse vegetation types is needed, but the results from the semi-arid site are encouraging and indicate that the model could be a potentially costeffective means of estimating FRB stock.

Acknowledgements: The authors would like to acknowledge Madonna B. Hoffmann and Dr Steven G. Bray both of the Queensland Department of Primary Industries and Fisheries for providing data for the mesic site. We thank the reviewers, Dr P. Vanninen and 

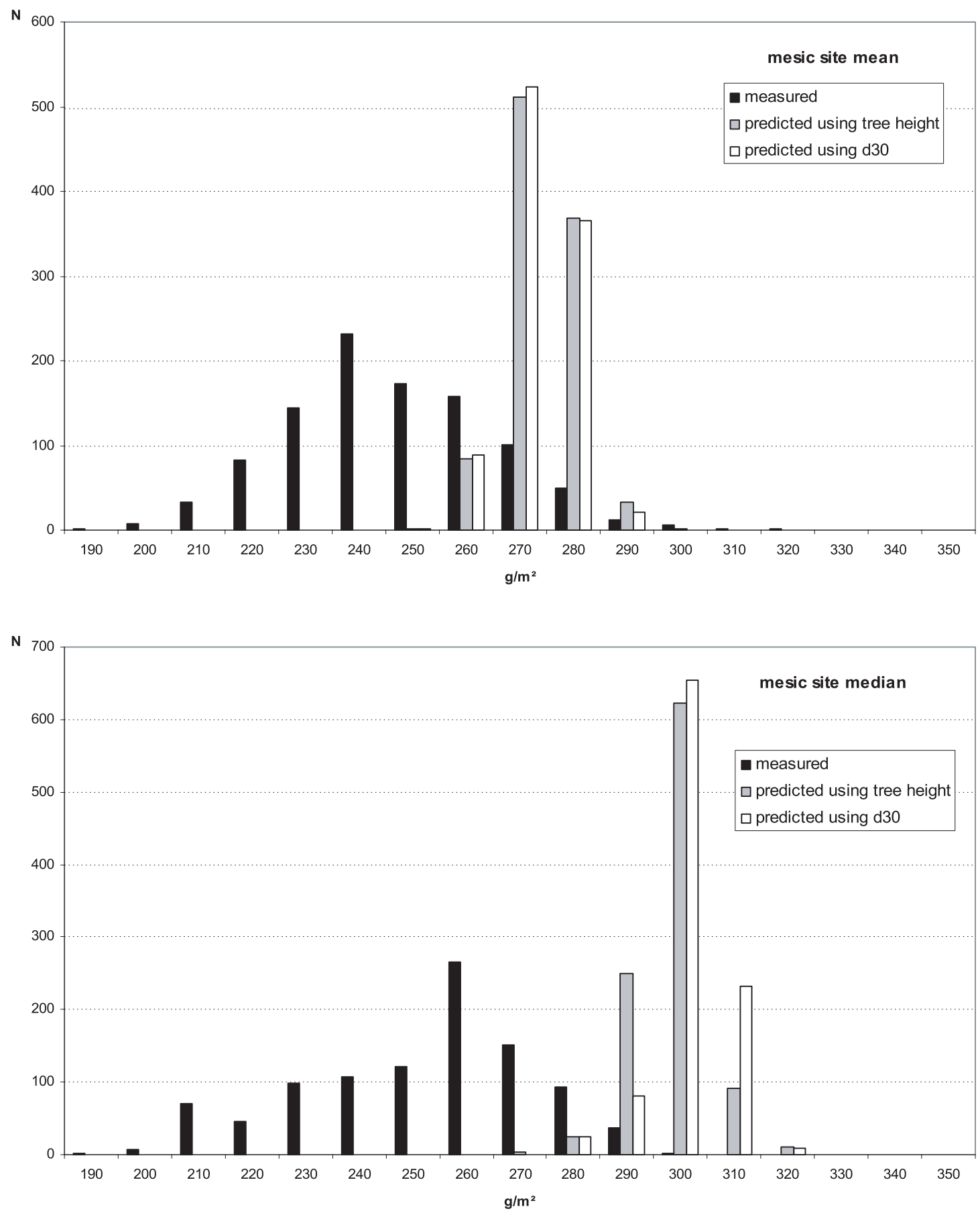

Figure 3. Frequency distributions of the bootstrap means and medians for the mesic site.

anonymous, whose comments helped improve the manuscript. The work was supported by the Cooperative Research Centre for Greenhouse Accounting.

\section{REFERENCES}

[1] Ammer C., Wagner S., Problems and options in modelling fine-root biomass of single mature Norway spruce trees at given points from stand data, Can. J. For. Res. 32 (2002) 581-590.
[2] Ammer C., Wagner S., An approach for modelling the mean fineroot biomass of Norway spruce stands, Trees 19 (2005) 145-153.

[3] Böhm W., Methods of studying root systems, Springer-Verlag, Berlin, 1979.

[4] Bolte A., Hertel D., Ammer C., Schmid I., Nörr R., Kuhr M., Redde N., Freilandmethoden zur Untersuchung von Baumwurzeln, Forstarchiv 74 (2003) 240-262.

[5] Chen W., Zhang Q., Cihlar J., Bauhus J., Price D.T., Estimating fineroot biomass and production of boreal and cool temperate forests 
using aboveground measurements: a new approach, Plant Soil 265 (2004) 31-46.

[6] Curt T., Coll L., Prévosto B., Balandier P., Kunstler G., Plasticity in growth, biomass allocation and root morphology in beech seedlings as induced by irradiance and herbaceous competition, Ann. For. Sci. 62 (2005) 51-60.

[7] Jackson R.B., Caldwell M.M., Geostatistical patterns of soil heterogeneity around individual perennial plants, J. Ecol. 81 (1993) 683-692.

[8] Jackson R.B., Mooney H.A., Schulze E.D., A global budget for fine root biomass, surface area, and nutrient contents, Proc. Natl. Acad. Sci. USA 94 (1997) 7362-7366.

[9] Krull E.S., Bray S.G., Assessment of vegetation change and landscape variability by using stable carbon isotopes of soil organic matter, Aust. J. Bot. 53 (2005) 651- 661.

[10] Kurz W.A., Beukema S.J., Apps M.J., Estimation of root biomass and dynamics for the carbon budget model of the Canadian forest sector, Can. J. For. Res. 26 (1996) 1973-1979.

[11] Lee E.H., Tingey D.T., Beedlow P.A., Johnson M.G., McKane R.B., A spatial analysis of fine-root biomass from stand data in the Pacific Northwest, Can. J. For. Res. 34 (2004) 2169-2180.

[12] Li Z., Kurz W.A., Apps M.J., Beukema S.J., Belowground biomass dynamics in the carbon budget model of the Canadian forest sector: recent improvements and implications for the estimation of NPP and NEP, Can. J. For. Res. 33 (2003) 126-136.

[13] Ludlow M.M., Troughton J.H., Jones R.J., A technique for determining the proportion of $\mathrm{C}_{3}$ and $\mathrm{C}_{4}$ species in plant samples using stable natural isotopes of carbon, J. Agric. Sci. 87 (1976) 625-632.

[14] Madeira M.V., Fabiao A., Pereira J.S., Araujo M.C., Ribeiro C., Changes in carbon stocks in Eucalyptus globulus labill. plantations induced by different water and nutrient availability, For. Ecol. Manage. 171 (2002) 75-85.

[15] Nielsen C.C.N., Mackenthun G., Die horizontale Variation der Feinwurzelintensität in Waldböden in Abhängigkeit von der Bestockungsdichte. Eine rechnerische Methode zur Bestimmung der "Wurzelintensitäts-Glocke" an Einzelbäumen, Allg. Forst- u. Jagdztg. 162 (1991) 112-119.
[16] Pemán J., Voltas J., Gil-Pelegrin E., Morphological and functional variability in the root system of Quercus ilex L. subject to confinement: consequences for afforestation, Ann. For. Sci. 63 (2006) $425-430$.

[17] Quinn G.P., Keough M.J., Experimental design and data analysis for biologists, Cambridge, New York, Port Melbourne, Madrid, Cape Town, Cambridge University Press, 2002.

[18] Robinson D., Resource capture by localised root proliferation: why do plants bother? Ann. Bot. 77 (1996) 179-185.

[19] Schenk H.J., Jackson R.B., Rooting depths, lateral root spreads and below-ground/above-ground allometries of plants in water-limited ecosystems, J. Ecol. 90 (2002) 480-494.

[20] Schulze E.-D., Beck E., Müller-Hohenstein K., Plant Ecology, Springer Verlag, Berlin, Heidelberg, New York, 2005.

[21] Stone E.L., Kalisz P.J., On the maximum extent of tree roots, For. Ecol. Manage. 46 (1991) 59-102.

[22] Sudmeyer R.A., Speijers J., Nicholas B.D., Root distribution of Pinus pinaster, P. radiata, Eucalyptus globulus and E. kochii and associated soil chemistry in agricultural land adjacent to tree lines, Tree Physiol. 24 (2004) 1333-1346.

[23] Vogt K.A., Vogt D.J., Bloomfield J., Analysis of some direct and indirect methods for estimating root biomass and production of forests at the ecosystem level, Plant Soil 200 (1998) 71-89.

[24] Zerihun A., Montagu K.D., Belowground to aboveground biomass ratio and vertical root distribution responses of mature Pinus radiata stands to phosphorus fertilisation at planting, Can. J. For. Res. 34 (2004) 1883-1894.

[25] Zerihun A., Montagu K.D., Hoffmann M.B., Bray S.G., Patterns of belowground and aboveground biomass in Eucalyptus populnea woodland communities of northeast Australia along a rainfall gradient, Ecosystems 9 (2006) 501-515.

[26] Zohar Y., Root distribution of eucalypt shelterbelts, For. Ecol. Manage. 12 (1985) 305-307. 